\title{
Diversity of Adult Caddisfly (Trichoptera) in Two Intermittent Streams During Dry Season in Phayao Province, Thailand
}

\author{
Arthit NUNTAKWANG ${ }^{1, *}$, Decha THAPANYA ${ }^{2}$ and Hakan BOZDOĞAN ${ }^{3}$ \\ ${ }^{I}$ Department of Biology, School of Science, University of Phayao, Phayao 50200, Thailand \\ ${ }^{2}$ Department of Biology, Faculty of Science, Chiang Mai University, Chiang Mai 51000, Thailand \\ ${ }^{3}$ Department of Plant and Animal Production, Vocational School of Technical Sciences, \\ University of Kirşehir, Ahi Evran 40100, Turkey
}

('Corresponding author's e-mail: natsuyazumi@gmail.com)

Received: 5 November 2019, Revised: 17 June 2020, Accepted: 19 July 2020

\begin{abstract}
The effect of anthropogenic activities on natural intermittent stream and diversity of adult caddisfly were studied at the University of Phayao, Thailand. The caddisfly adults were collected monthly from 2 intermittent streams (the Huai Thub Chang and Huai Luang streams) from February to May 2015 (cooldry to hot-dry season) using a black-light trap. Huai Thub Chang stream received wastewater from the oxidation pond, while Huai Luang stream was affected by an agricultural field of the university. Both streams are located in a deciduous forest. The 14 species of 7 families were collected and identified. Cheumatopsyche lucida (Hydropsychidae) and Leptocerus dirghachuka (Leptoceridae) were found in both streams. C. lucida was the most abundant species. Micrasema turbo, Amphipsyche meridiana, $C$. globosa, Diplectrona lavinia, Macrostemum dohrni, Marilia sumatrana, and Wormaldia relicta were found only in Huai Thub Chang stream, whereas C. dhanikari, Lepidostoma doligung and Chimarra toga were found only in Huai Luang stream. A high number of C. lucida in both streams from February to April reflected a drought effect on the emergence of the caddisflies. Huai Thub Chang stream had a higher diversity of Trichoptera species than Huai Luang stream because of the variety of substrate types which were suited for the larval stage, especially hydropsychids.
\end{abstract}

Keywords: Caddisfly, Intermittent streams, Dry season, Trichoptera species, Hydropsychids, Phayao

\section{Introduction}

Caddisflies are the main group of aquatic insects; their larval stage inhabits many types of aquatic ecosystems, and their adults form to live in the terrestrial ecosystem. Their larva morphology is similar to butterfly larva. Their adults are also similar to the micro moth. The 14,548 described species are distributed over the globe [1,2], while some families are worldwide in occurrence; others are restricted to either the northern or the southern hemisphere [3]. In Thailand, studies of trichoptera have been conducted since 1978, where it was performed by Malicky and Chantaramongkol [4]. These insects have been continuously studied, mainly in northern Thailand, until now, and there have been 1,004 species reported [5]. In Northern Thailand, investigations on caddisflies were done in 2007 by Nuntakwang et al. [6] and also in some specific areas such as Doi Suthep-Pui (Chiang Mai Province) [7-9], Champathong Waterfall (Phayao Province) [10], and Mae Keong Waterfall (Phare Province) [11].

Intermittent streams are common inland freshwater habitats around the world, but these habitats are poorly studied compared to permanent streams [12]. These streams flow seasonally when the groundwater tables are elevated over the streambed by the influence of precipitation and rain. In dry seasons, the streams will be dry because the groundwater tables are reduced under the stream bed level [13]. There are a few studies on caddisfly in intermittent stream around the worlds. 
The University of Phayao is located in Phayao province, Thailand. The campus is surrounded by a deciduous forest and natural intermittent streams. There are 2 intermittent streams, which are outlets from the reservoir of the university (Figure 1). Huai Thab Chang stream is located to the north of the university. It receives domestic water from the university and flows to the second reservoir, which is used for local agriculture outside the university. Huai Luang stream is located to the east of the university. It was modified to be an irrigation canal that receives water from the reservoir of the university. The expansion of the university during the past 5 years caused deterioration on land and water. Some natural intermittent streams were used to receive untreated wastewater from domestic and agricultural areas, which affected aquatic fauna. To study the impact of the dry season and stream reach type on the stream and fauna, the adult of the caddisfly was chosen to study, due to them being very common in these streams, especially hydropsychid larva.

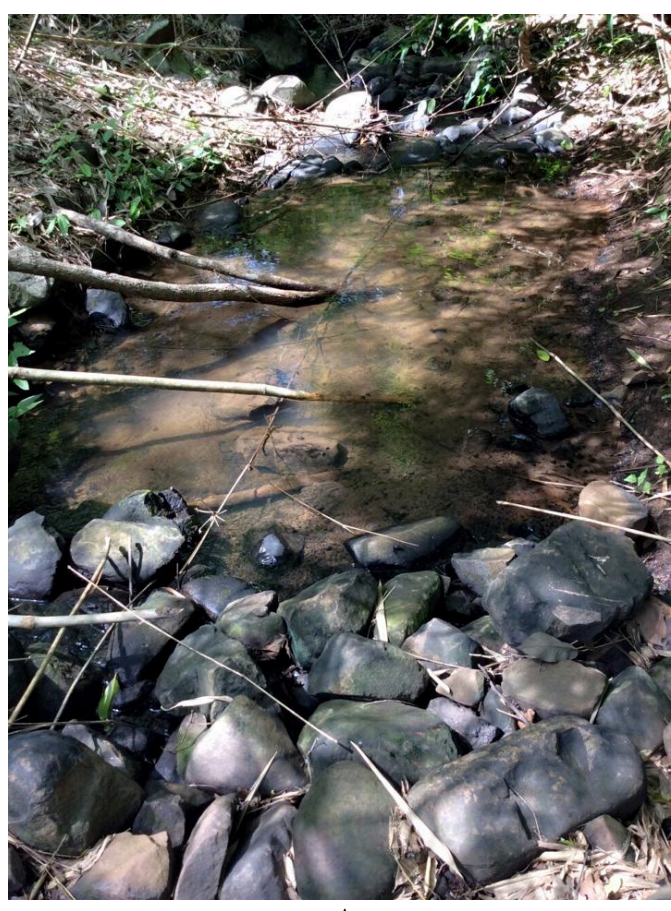

A

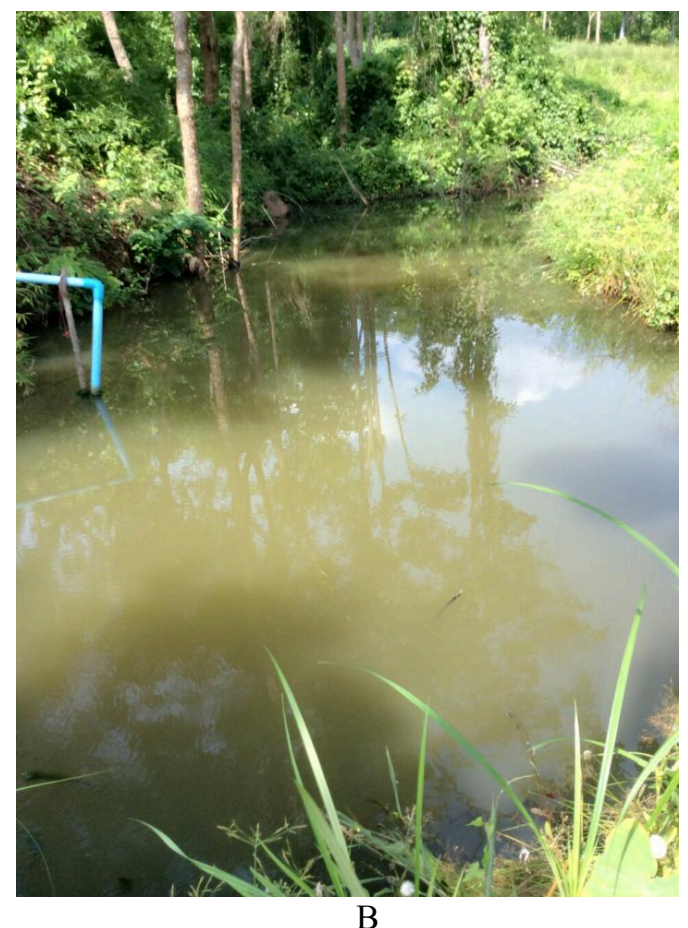

$\mathrm{B}$

Figure 1 Sampling sites (A: Huai Thab Chang stream, B: Huai Luang) in 2 intermittent streams of the University of Phayao, Thailand.

\section{Materials and methods}

\section{Study area}

Two intermittent streams, Huai Thab Chang and Haui Luang, were selected for setting a black-light trap to collect Trichoptera (adult) overnight. Each stream was divided into 2 sampling points, Huai Tab Chang 1 (HTC1), Huai Tab Chang 2 (HTC2), Haui Luang 1 (HL1), and Haui Luang 2 (HL2), respectively (Figure 2). The materials were collected once a month from February to May 2015 during a seasonal transition (late cool dry season to hot dry season). 


\section{Material collection}

Trichoptera (adult) were collected using a portable black-light trap set (10-W fluorescent tube, 12Volt DC battery) suspended on a plastic tray containing a detergent solution. Light traps were placed near the stream margin before sunset and left overnight (Figure 3). On the morning of the next day, the insect material was transferred into $80 \%$ ethyl alcohol and transported to the laboratory.

\section{Material identification}

The caddisflies (male) were sorted and examined under a dissecting stereomicroscope. The last 2 abdominal segments of adult male genitalia were separated and cleared by heating in $10 \% \mathrm{NaOH}$ at $70{ }^{\circ} \mathrm{C}$ for 30 - $45 \mathrm{~min}$. Species level identification was done by using the Atlas of Southeast Asian Trichoptera [5].

\section{Data analyses}

The individual number of each species was counted and summarized. The total number of individuals was transformed into a log number of each species. A Sorensen's similarity index was used to compare the trichopteran species in each sampling point [14].

Percentage of Sørensen index (Sørensen's similarity coefficient) $C_{s}=[2 j /(a+b)] \times 100$

where $j=$ Number of species found in both sites

$\mathrm{a}=$ Number of species in site A

$\mathrm{b}=$ Number of species in site $\mathrm{B}$

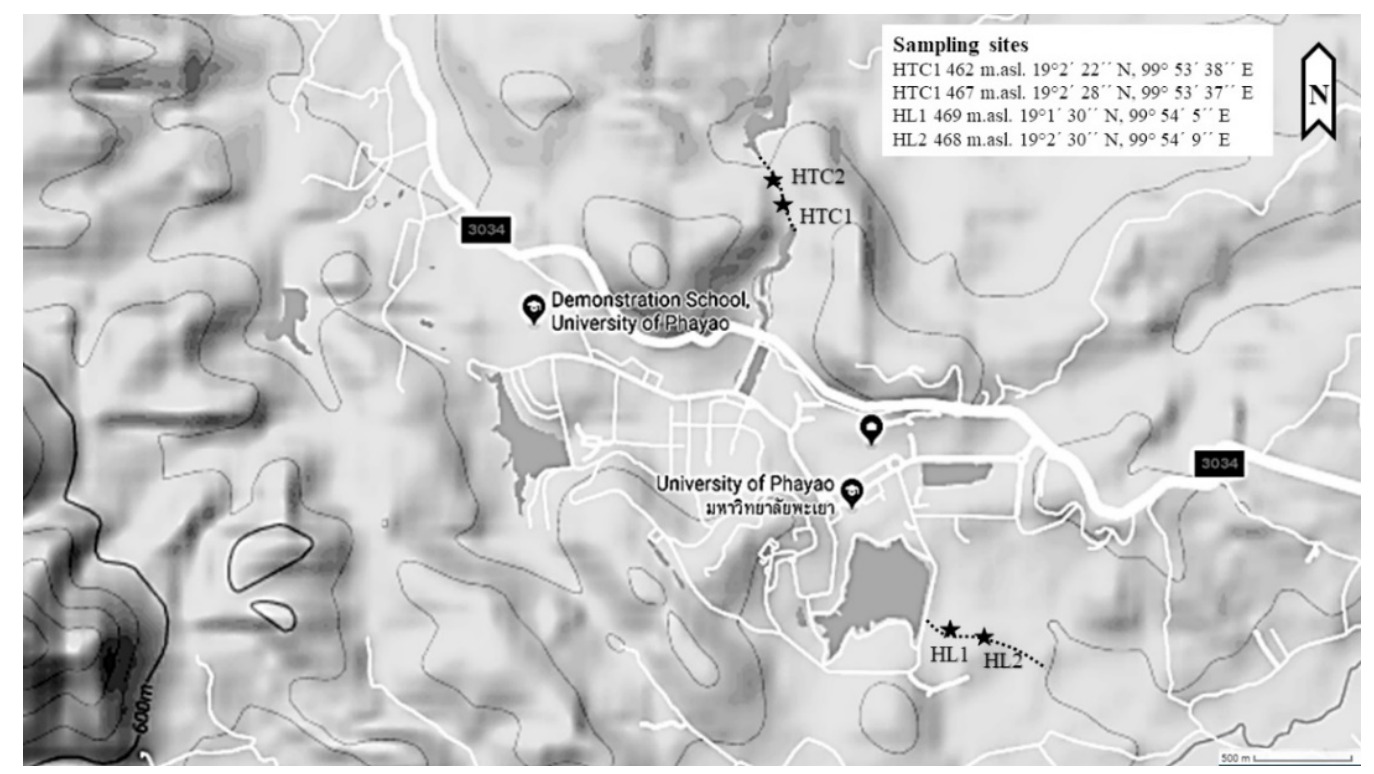

Figure 2 The sampling points of Huai Thub Chang stream and Huai Luang stream. 
http://wjst.wu.ac.th

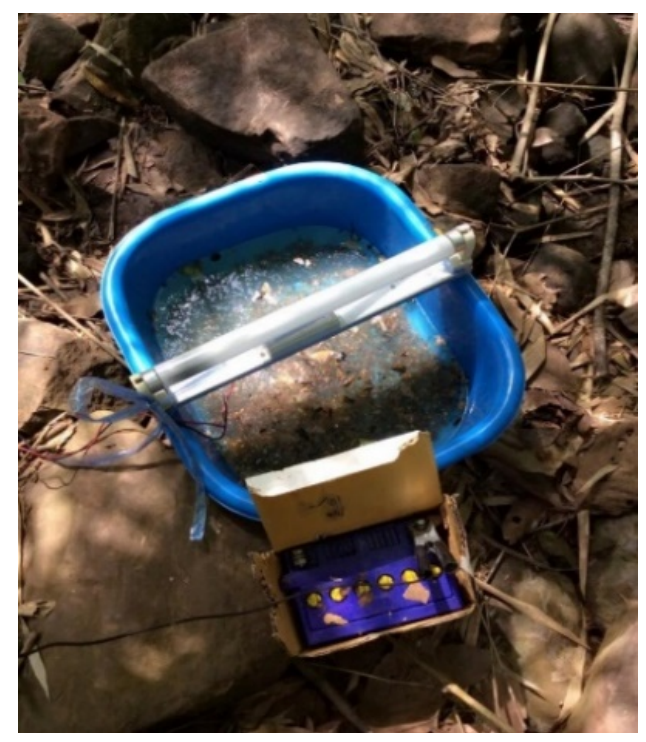

Figure 3 The black-light traps were placed to collect the adult caddisflies overnight.

\section{Results and discussion}

\section{Species abundance}

14 species of adult caddisflies were collected, listed in Table 1. Cheumatopsyche lucida (Hydropsychidae) and Leptocerus dirghachuka (Leptoceridae) (Figure 4) were found in both Huai Thab Chang and Huai Luang streams.C. lucida had the highest species abundance.Micrasema turbo, Amphipsyche meridiana, Cheumatopsyche globosa, Diplectrona lavinia, Macrostemum dohrni, Marilia sumatrana, and Wormaldia relicta were found only in Huai Thab Chang stream, whereas Cheumatopsyche dhanikari, Lepidostoma doligung, and Chimarra toga were found only in Haui Luang stream. The location of the stream and the dispersal ability of the species can be used to explain a difference of species abundance in these 2 streams. Some species fly very well, but others can fly only a few kilometers. The continuity of habitat is also important and could benefit or adversely affect caddisfly communities. These 2 streams were separated by road and the University campus. This can be a barrier to limit the distribution of some species that cannot be found in other streams.
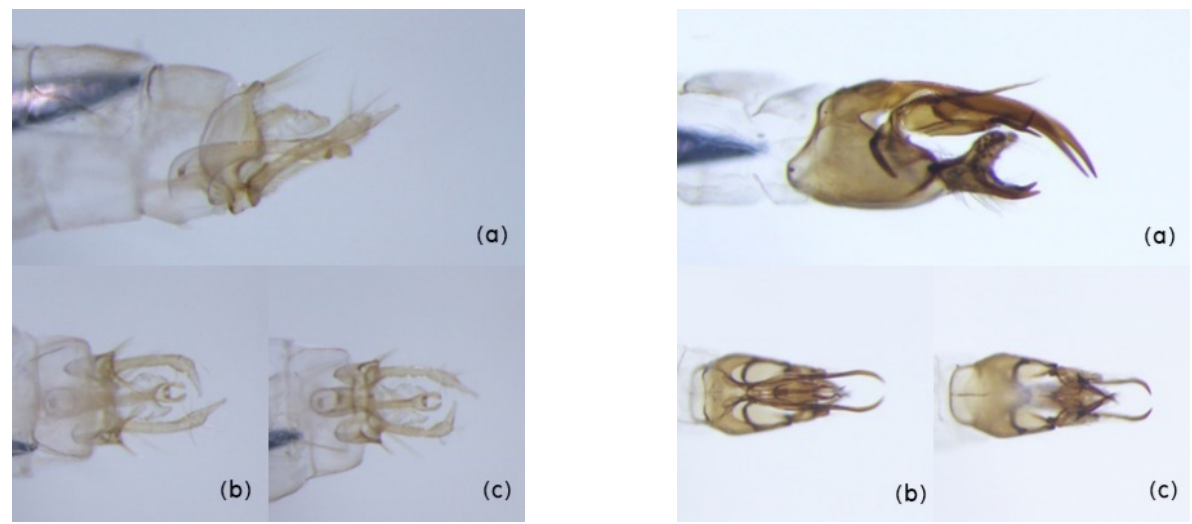

Figure 4 Left: Male genitalia of Cheumatopsyche lucida (a) lateral (b) dorsal (c) ventral. Right: Male genitalia of Leptocerus dirghachuka (a) lateral (b) dorsal (c) ventral. 


\section{Huai Thub Chang stream}

There were 3 emergence periods of caddisflies. The $1^{\text {st }}$ period was in February, in which Cheumatopsyche globosa and Chimarra akkaorum were found. The $2^{\text {nd }}$ period was in April, where many species were presented-Amphipsyche meridiana, Cheumatopsyche lucida, Diplectrona lavinia Hydroptila thuna, Leptocerus dirghachuka, Marilia sumatrana, and Wormaldia relicta. The $3^{\text {rd }}$ period was in May, in which Micrasema turbo and Macrostemum dohrni were found. The increasing caddisfly apparently reflected a drought effect on the emergence of the adult caddisflies, which started from February to April, especially on C. lucida, which was high in abundance in this stream (Table 1). Their number decreased from April to May, during which the stream water became too dry (Figure 5).

Table 1 Species list and population of male caddisflies which were collected from February to May 2015 in Huai Tab Chang stream and Huai Luang stream.

\begin{tabular}{llcccc}
\hline Family & Trichoptera species & HTC1 & HTC2 & HL1 & HL2 \\
\hline Hydroptilidae & Hydroptila thuna OLAH 1989 & 14 & 0 & 262 & 8 \\
\hline Philopotamidae & Chimarra akkaorum C\&M 1986 & 1 & 1 & 0 & 1 \\
\hline & Chimarra toga M\&C 1993 & 0 & 0 & 0 & 7 \\
\hline & Wormaldia relicta MARTYNOV 1935 & 1 & 0 & 0 & 0 \\
\hline Hydropsychidae & Amphipsyche meridiana ULMER 1909 & 1,024 & 43 & 0 & 0 \\
\hline & Cheumatopsyche dhanikari MALICKY 1979 & 0 & 0 & 0 & 14 \\
\hline & Cheumatopsyche globosa ULMER 1901 & 1 & 0 & 0 & 0 \\
\hline & Cheumatopsyche lucida ULMER 1907 & 13,980 & 1,949 & 777 & 704 \\
\hline Odontoceridae & Diplectrona lavinia MALICKY & 2 & 0 & 0 & 0 \\
\hline Lepidostomatidae & Lepidostoma doligung MALICKY 1979 & 1 & 0 & 0 & 0 \\
\hline Brachycentridae & Micrasema turbo M\&C 1992 & 1 & 0 & 0 & 0 \\
\hline Leptoceridae & Leptocerus dirghachuka GORDON & 1 & 0 & 1 & 0 \\
\hline \&otal families (7) & Individual number & 11 & 15 & 19 & 8 \\
\hline Total species (14) & Species number & 15,037 & 2,008 & 1,059 & 742 \\
\hline
\end{tabular}



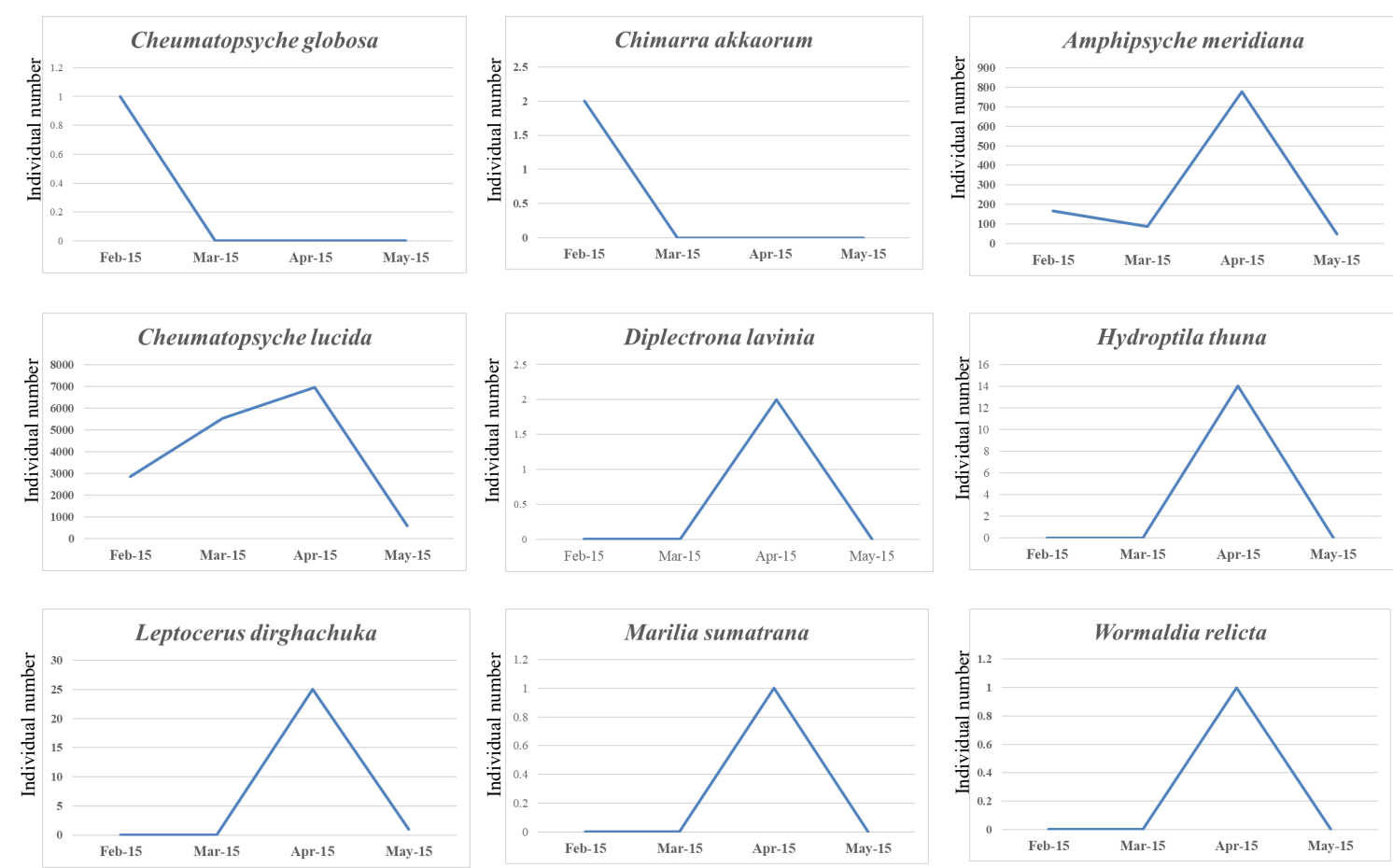
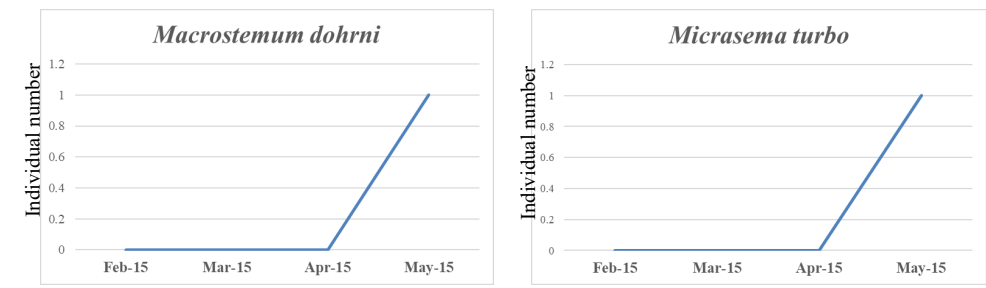

Figure 5 Individual number of caddisfly species and their emergence periods in Huai Thub Chang stream during February 2015 to May 2015.

\section{Huai Luang Stream}

There were 4 emergence periods of caddisfly. The $1^{\text {st }}$ period was in February, in which Hydroptila thuna and Chimarra akkaorum were found. The $2^{\text {nd }}$ period was in March, in which Cheumatopsyche dhanikari, Cheumatopsyche lucida, and Chimarra toga were found. The $3^{\text {rd }}$ period and $4^{\text {th }}$ period were in April and May, in which only Leptocerus dirghachuka and Lepidostoma doligung were collected, respectively (Figure 6).

According to Prommi et al. [15], C. lucida was collected from Mae Tao and Mae Ku watersheds in Tak province. This species is found only in some areas in Northern Thailand. Its distribution is quietly specific to stream reach, in which the stream bed consists mainly of bedrock, gravel, sand, small stones, and some large boulders, which is similar to Huai Thub Chang stream and Huai Luang stream in this research. Due to the feeding habits of the larval stage, as a filter feeder, the species requires a stable substrate to build an attached case over a substrate to collect fine particulate organic matter in a stream flow $[16,17]$.

A Sorensen's similarity index shows that the highest similarity was $63 \%$ (HTC1-HTC2) and the lowest similarity was $40 \%$ (HTC1-HL1) (Figure 7). These results show that the species of caddisfly among these 2 streams were located in the same forest were different. 

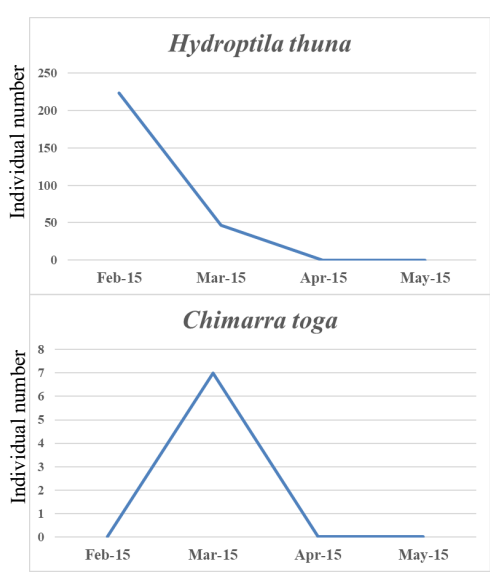

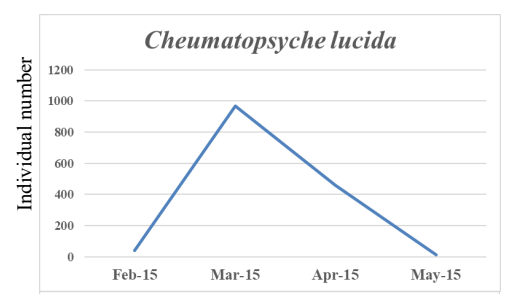

Mar-15 Apr-15 Ma

Cheumatopsyche dhanikari

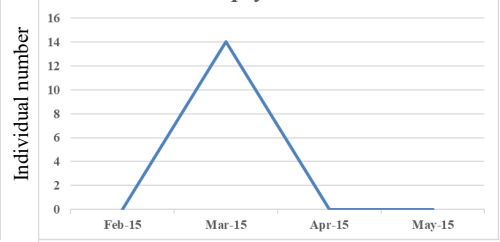

Lepidostoma doligung
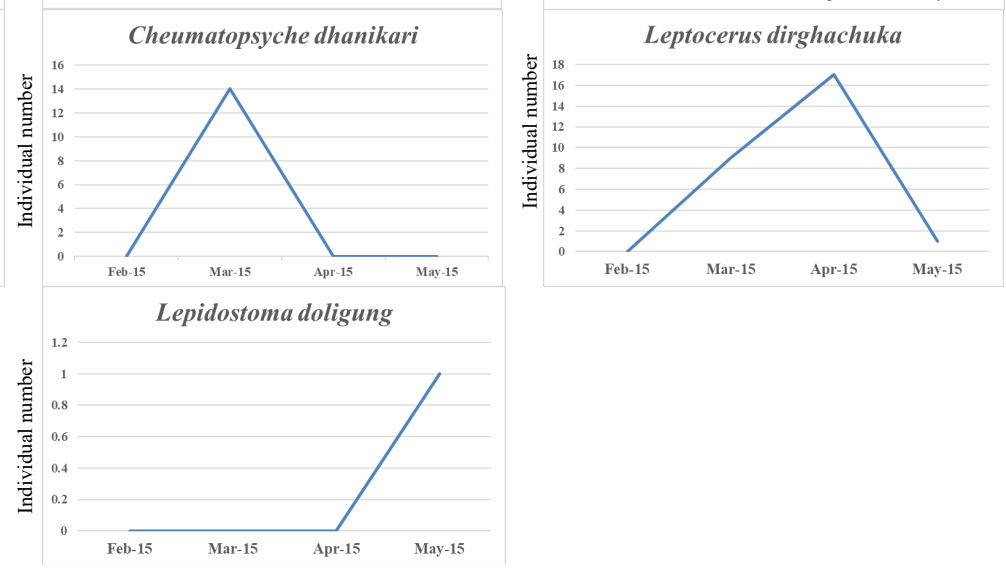

Figure 6 Individual number of caddisfly species and their emergence periods in Huai Luang stream from February 2015 to May 2015.

\begin{tabular}{|c|c|c|c|c|}
\cline { 2 - 5 } \multicolumn{1}{c|}{} & HTC1 & HTC2 & HL1 & HL2 \\
\hline HTC1 & & $\bullet$ & & \\
\hline HTC2 & 63 & & & $\bullet$ \\
\hline HL1 & 40 & 44 & & $\bullet$ \\
\hline HL2 & 47 & 55 & 60 & \\
\hline \multicolumn{4}{|c|}{$>75 \%$} \\
\hline
\end{tabular}

Figure 7 Sorensen's similarity percentage of caddisfly species, comparing 4 sampling points.

\section{Conclusions}

The intermittent streams in the deciduous forest, substratum type, had affected the diversity of trichoptera. The stream reach of Huai Thub Chang stream is pool-riffle and step-pool, and predominant bed materials are gravel cobble and boulder, while the stream reach of Huai Luang stream is pool-riffle, and predominant bed materials are gravel and some debris materials. Both streams had a dominant sediment source of fluvial, bank erosion, inactive channels, and debris flows [16]. According to the species richness of Huai Thub Chang stream, which is located in the natural deciduous forest, and Huai Luang stream, which was transformed into an agricultural field, these 2 streams had a low diversity during the dry season, except for HTC1, which had a higher species number.Decreasing water had affected the hydropsychid species, especially $C$. lucida, which had high abundance in this area. This is clearly similar to Huai Luang stream, in that the number of $C$. lucida decreased from the same time as 
Huai Thub Chang stream (Figure 8). Some species, such as Chimarra akkaorum and Leptocerus dirghachuka which were found in both streams, showed the same emergence period in March and April. Environmental factors, such as substratum in each stream, affected the species number of caddisfly due to them providing a different microhabitat and material for caddisfly in the larval stage to live and build their cases. The major substrate of HCT1 was a big boulder that provided a proper habitat for hydropsychid (net-spinning caddisfly) and philopotamid (finger-net caddisfly) species. Larvae of these groups were filtered feeders, which need a high stable substrate to build fixed cases and fast water currents to feed seston [17]. The substrate of HTC2, HL1, and HL2 were cobbled, sand, and clay. The water current was slow. This condition is suited for deposit feeder larva, such as Hydroptilidae, Lepidostomatidae and Leptoceridae.

In Thailand, there are few studies on trichoptera in intermittent streams, especially in dry deciduous forest. C. lucida in these 2 streams may be used as a bioindicator for the drought period of the dry season for this area, but the correlation between its larval stage and water discharge is a necessary study to find out its function in ecosystem service $[18,19]$. Annual study is necessary to find out the seasonal pattern of the emergence, which will lead to understanding of the phenology of caddisfly in intermittent streams.

\section{Acknowledgements}

Thanks to the School of Science, the University of Phayao, for a research grant and research facilities. Thanks to the Aquatic Insect Research Unit, Department of Biology, Faculty of Science, Chiang Mai University, for checking the unknown materials.

\section{References}

[1] FCD Moor and VD Ivanov. Global diversity of caddisflies (Trichoptera: Insecta) in freshwater. Hydrobiologia 2007; 595, 393-407.

[2] JC Morse. Trichoptera World Checklist, Available at: http://www.clemson.edu/cafls/departments /esps/database/trichopt/index.htm, accessed November 2019.

[3] DD Williams and BW Feltmate. Aquatic insects. CAB international, 1992.

[4] H Malicky. On some Rhyacophila from Doi Suthep Mountain, northern Thailand. Trichoptera Newsletter 1987; 14, 27-9.

[5] H Malicky. Atlas of Southeast Asian Trichoptera. Biology Department, Science Faculty, Chiang Mai University, 2010.

[6] A Nuntakwang, P Chantaramongkol and GW Courtney. Biodiversity and biogeographic connections of Trichoptera from mountain streams of northern Thailand. $I n$ : Proceedings of the $12^{\text {th }}$ International Symposium on Trichoptera. 2006, p. 259-62.

[7] P Chantaramongkol, P McQuillan and S Promkutkaew. Analysis of Trichoptera adult seasonality from Huay Hoo Kaow stream, Chiang Mai Zoo, Doi Suthep, Thailand.In: Proceedings of the $9^{\text {th }}$ International Symposium on Trichoptera, Chiang Mai. 1998, p. 469-74.

[8] T Prommi and P Chantaramongkol. A preliminary survey of adult Trichoptera communities in Thongphaphum District, Kanchanaburi Province, Thailand. In: Proceedings of the $11^{\text {th }}$ International Symposium on Trichoptera, Tokai University Press, Kanagawa, 2003, p. 355-61.

[9] D Thapanya, P Chantaramongkol and H Malicky. An updated survey of caddisflies (Trichoptera, Insecta) from Doi Suthep-Pui and Doi Inthanon National Parks, Chiang Mai Province, Thailand. Nat. Hist. J. Chulalongkorn Univ. 2004; 4, 21-40.

[10] T Prommi, K Seetapan and P Thamsenanupap. Diversity and seasonality of caddisflies ( Insecta: Trichoptera) at Champathong waterfall, northern Thailand. SDU Res. J. 2012; 5, 125-37.

[11] J Nawvong and P Chantaramongkol. Effects of discharge and stream flow regulation on Trichoptera communities in northern Thailand. In: Proceedings of the $11^{\text {th }}$ International Symposium on Trichoptera, Tokai University Press, Kanagawa. 2003, p. 309-15.

[12] R Stubbing, R Chadd, N Cid, Z Csabai, M Miliša, M Morais, A Munné, P Pařil, V Pešić, I Tziortzis, RCM Verdonschot and T Datry. Biomonitoring of intermittent rivers and ephemeral streams in 
Europe: Current practice and priorities to enhance ecological status assessments. Sci. Total Environ. 2018; 618, 1096-113.

[13] OT McDonough, JD Hosen and MA Palmer. Temporary streams: The hydrology, geography, and ecology of non-perennially flowing waters. In: HS Elliot and LE Martin (Eds.). River ecosystem: Dynamic, management and conservation. Nova Science Publishers, New York, 2011, p. 259-89.

[14] AE Maguran. Ecological diversity and its measurement. Princeton University Press, 1988, p. 94-95.

[15] TO Prommi, P Luadee and T Chareonviriyaphap. Biodiversity of adult Trichoptera and water quality variables in streams, northern Thailand. APCBEE Proc. 2014; 10, 292-298.

[16] FR Hauer and GA Lamberti. Methods in stream ecology. $2^{\text {nd }}$ ed. Elsevier Academic Press, 2007, p. 23-38.

[17] D Dudgeon. Tropical Asian streams. Hong Kong University Press, 1999, p. 356-412.

[18] JC Morse, PB Frandsen, W Graf and JA Thomas. Diversity and ecosystem services of Trichoptera. Insects 2019; 10, 125.

[19] B Stastzner. Population dynamics of Hydropsychidar (Insecta; Trichoptera) in the N'Zi River (Ivory Coast), a temporary stream partly treated with the insecticide Chlorophoxim. Rev. Hyydrobiol. Trop. $1982 ; \mathbf{1 5}, 157-76$. 